\title{
Halofuginone inhibits colorectal cancer growth through suppression of Akt/mTORC1 signaling and glucose metabolism
}

\author{
Guo-Qing Chen ${ }^{1,2}$, Cheng-Fang Tang ${ }^{3,4}$, Xiao-Ke Shi ${ }^{1}$, Cheng-Yuan Lin ${ }^{1}$, Sarwat \\ Fatima $^{1}$, Xiao-Hua Pan ${ }^{5}$, Da-Jian Yang ${ }^{2}$, Ge Zhang ${ }^{1}$, Ai-Ping Lu ${ }^{1}$, Shu-Hai Lin ${ }^{1,3}$ and \\ Zhao-Xiang Bian ${ }^{1}$ \\ ${ }^{1}$ Laboratory of Brain and Gut Research, Center for Clinical Research on Chinese Medicine, School of Chinese Medicine, Hong \\ Kong Baptist University, Hong Kong SAR, China \\ ${ }^{2}$ Chongqing Academy of Chinese Materia Medica, Chongqing, China \\ ${ }^{3}$ Department of Chemistry and State Key Laboratory of Environmental and Biological Analysis, Hong Kong Baptist University, \\ Hong Kong SAR, China \\ ${ }^{4}$ Instrument and Testing Center, Sun Yat-Sen University, Guangzhou, China \\ ${ }^{5}$ Shen Zhen People's Hospital, Shenzhen, China \\ Correspondence to: Shu-Hai Lin, email: linshu@hkbu.edu.hk
}

Zhao-Xiang Bian, email: bzxiang@hkbu.edu.hk

Keywords: halofuginone, anticancer activity, colorectal cancer, Akt/mTORC1, glucose metabolism

Received: March 11, $2015 \quad$ Accepted: May 31, $2015 \quad$ Published: June 08, 2015

This is an open-access article distributed under the terms of the Creative Commons Attribution License, which permits unrestricted use, distribution, and reproduction in any medium, provided the original author and source are credited.

\section{ABSTRACT}

The Akt/mTORC1 pathway plays a central role in the activation of Warburg effect in cancer. Here, we present for the first time that halofuginone (HF) treatment inhibits colorectal cancer (CRC) growth both in vitro and in vivo through regulation of Akt/mTORC1 signaling pathway. Halofuginone treatment of human CRC cells inhibited cell proliferation, induced the generation of reactive oxygen species and apoptosis. As expected, reduced level of NADPH was also observed, at least in part due to inactivation of glucose-6-phosphate dehydrogenase in pentose phosphate pathway upon HF treatment. Given these findings, we further investigated metabolic regulation of HF through Akt/mTORC1-mediated aerobic glycolysis and found that HF downregulated Akt/mTORC1 signaling pathway. Moreover, metabolomics delineated the slower rates in both glycolytic flux and glucose-derived tricarboxylic acid cycle flux. Meanwhile, both glucose transporter GLUT1 and hexokinase-2 in glycolysis were suppressed in CRC cells upon HF treatment, to support our notion that HF regulates Akt/mTORC1 signaling pathway to dampen glucose uptake and glycolysis in CRC cells. Furthermore, HF retarded tumor growth in nude mice inoculated with HCT116 cells, showing the anticancer activity of HF through metabolic regulation of Akt/mTORC1 in CRC.

\section{INTRODUCTION}

More than 1.2 million cases are diagnosed with colorectal cancer (CRC) every year, and more than 600000 die from the disease worldwide. CRC is responsible for $8 \%$ of all cancer deaths [1]. In United States, CRC is the second leading cause of death from cancer among adults [2]. As evidenced by genetic modifications, environmental impacts, diet and lifestyles, the underlying mechanisms of CRC have been intensively studied. Akt, also known as protein kinase $\mathrm{B}(\mathrm{PKB})$, which is overexpressing in a number of cancers including colorectal cancer, plays a key role in multiple cellular processes such as glucose metabolism, apoptosis, cell proliferation, transcription and cell migration [3]. Akt activates an array of downstream factors through phosphorylation and then regulates cellular metabolism which is rewired in cancer cells [4]. Of note, mammalian target of rapamycin complex 1 (mTORC1), is led by Akt through phosphorylation at Ser 2448. It has been reported the PI3K/Akt/mTOR signaling components were highly activated in glandular elements of colorectal 
carcinoma and colorectal adenomas with high-grade intraepithelial neoplasia [5], indicating that inhibitors of $\mathrm{PI} 3 \mathrm{~K} / \mathrm{Akt} / \mathrm{mTOR}$ signaling may serve as potential antiCRC agents.

The cellular metabolism could be regulated by Akt/mTORC1 and the downstream effectors. As a central activator of Warburg effect, mTORC1 can induce glycolytic enzymes in cancer cells [6]. The p70S6K controls lipid/sterol synthesis and switches glucose metabolism from glycolysis to pentose phosphate pathway (PPP) in cancer cells [7]. It is well known that oxidative arm of PPP is one of the major pathways for NADPH (the reduced form of nicotinamide adenine dinucleotide phosphate) production. NADPH is a strong reducing agent which can react with reactive oxygen species (ROS), allowing cancer cells to escape apoptosis [8]. Thus, activated p70S6K regulates redox state of cancer cells and promotes cancer cell growth. 4EBP1 is another well characterized mTORC1 downstream factor which inhibits the initiation of protein translation by binding and inactivating eIF4E (eukaryotic translation initiation factor 4E). Active mTOR regulates 4EBP1 inhibition, increasing glucose uptake and glycolysis [9]. Therefore, PI3K/Akt/ mTOR signaling pathway is thought to be very important for glucose and lipid metabolism in cancer cells. This pathway activates aerobic glycolysis (Warburg effect), leading to glucose being avidly consumed by cancer cells for energy demands and survival $[10,11]$.

Halofuginone (HF) is a derivative of the febrifugine which can be extracted from the Chinese herb Dichroa febrifuga Lour. (Changshan in Chinese) (Figure 1A) [12]. It has been used as anti-coccidial drug in animal husbandry for many years [13]. In the last two decades, $\mathrm{HF}$ has gained attention for its potential therapeutic effects in fibrotic disease by inhibiting alpha-1 type I collagen gene expression and collagen synthesis [14]. $\mathrm{HF}$ also has anticancer activity in bladder carcinoma by inhibiting tumor growth and metastasis through matrix metalloproteinase-2 $[15,16]$, prostate cancer [17], hepatocellular carcinoma [18], and also modulates the transforming growth factor beta (TGF- $\beta$ ) signaling pathway to inhibit acute promyelocytic leukemia as well as melanoma bone metastases [13, 19]. Particularly, HF has also been found to inhibit Th17 cell differentiation by activating the amino acid starvation response for regulating Stat3-dependent Th17 effector function and reducing established autoimmune inflammation [20, 21]. However, to our best knowledge, whether HF inhibits tumor growth in CRC has not been reported. The aim of this study, therefore, is to investigate the anticancer activity of $\mathrm{HF}$ in $\mathrm{CRC}$ through the inhibition of Akt/ mTORC1 signaling both in vitro and in vivo. Glucose metabolism and lipid profiles mediated by Akt/mTORC1 signaling pathway in CRC cells upon HF treatment were also depicted by applying metabolomics and lipidomics based on mass spectrometry.

\section{RESULTS}

\section{Halofuginone treatment inhibits proliferation and induces cell cycle arrest in G1/G0 phase}

The effect of HF in CRC cells was examined by performing MTT, colony formation, cell cycle and apoptosis assays as well as measurement of ROS and NADPH levels. As shown in Figure 1B, treatment with increasing concentrations ( 5 to $160 \mathrm{nM}$ ) of $\mathrm{HF}$ reduced CRC cell viability compared with the untreated control cells in time- and dose-dependent manners. A sharp decline in cell viability was also observed with increase of $\mathrm{HF}$ concentrations. The $\mathrm{IC}_{50}$ values were calculated to be $24.83 \mathrm{nM}, 5.82 \mathrm{nM}, 40.76 \mathrm{nM}, 47.61 \mathrm{nM}$ and 60.89 nM for SW480, HCT116, SW620, HT29 and DLD-1 respectively, after $48 \mathrm{~h}$-treatment. In addition, to further test HF toxicity in normal cells, we used non-transformed rat small intestinal epithelial cell line IEC-6 and human non-tumorigenic liver cell line MIHA treated with HF, and calculated $\mathrm{IC}_{50}$ values as $205.7 \mathrm{nM}$ and $261.9 \mathrm{nM}$ for IEC- 6 and MIHA respectively, after 48 h-treatment, indicating that $\mathrm{HF}$ exerts relatively low toxicity to these two non-tumorigenic cell lines (Figure 1C). Colony formation assay was also conducted for examining the effect of HF on CRC cell survival in vitro. HF treatment dose-dependently reduced cancer cell survival rates (Figure 1D). Furthermore, the effect of HF on cell cycle progression was tested in SW480 and HCT116 cell lines by PI staining, followed by FACS analysis. As shown in Figure 1E, after HF treatment for $12 \mathrm{~h}$, a dose-dependent arrest occurred in the G1/G0 phase of the CRC cells, indicating that the inhibitory effect of HF on CRC cell proliferation might be correlated with the arrest of G1/G0 cell cycle progression.

\section{Halofuginone induces apoptosis, increases ROS and decreases NADPH levels}

In the cell cycle distribution analysis, sub-G1 peaks in two cell lines also revealed that HF could induce apoptosis (Figure S1). To further determine the effect of HF-induced apoptosis, annexin V/PI dye staining was performed for quantitative analysis of the apoptotic cell percentage in both cell lines treated with increasing concentrations of HF for $12 \mathrm{~h}$. As shown in Figure 2A, $\mathrm{HF}$ treatment increases the percentage of both early and late apoptotic cells compared with the untreated control. Consistently, HF treatment profoundly increased the expression of cleaved Caspase- 3 and cleaved PARP in a dose-dependent manner as demonstrated by Western blot analysis (Figure 2B). The induction of apoptosis, at least in part due to ROS generation, has been implicated [22]. Therefore, we tested whether HF treatment can enhance 

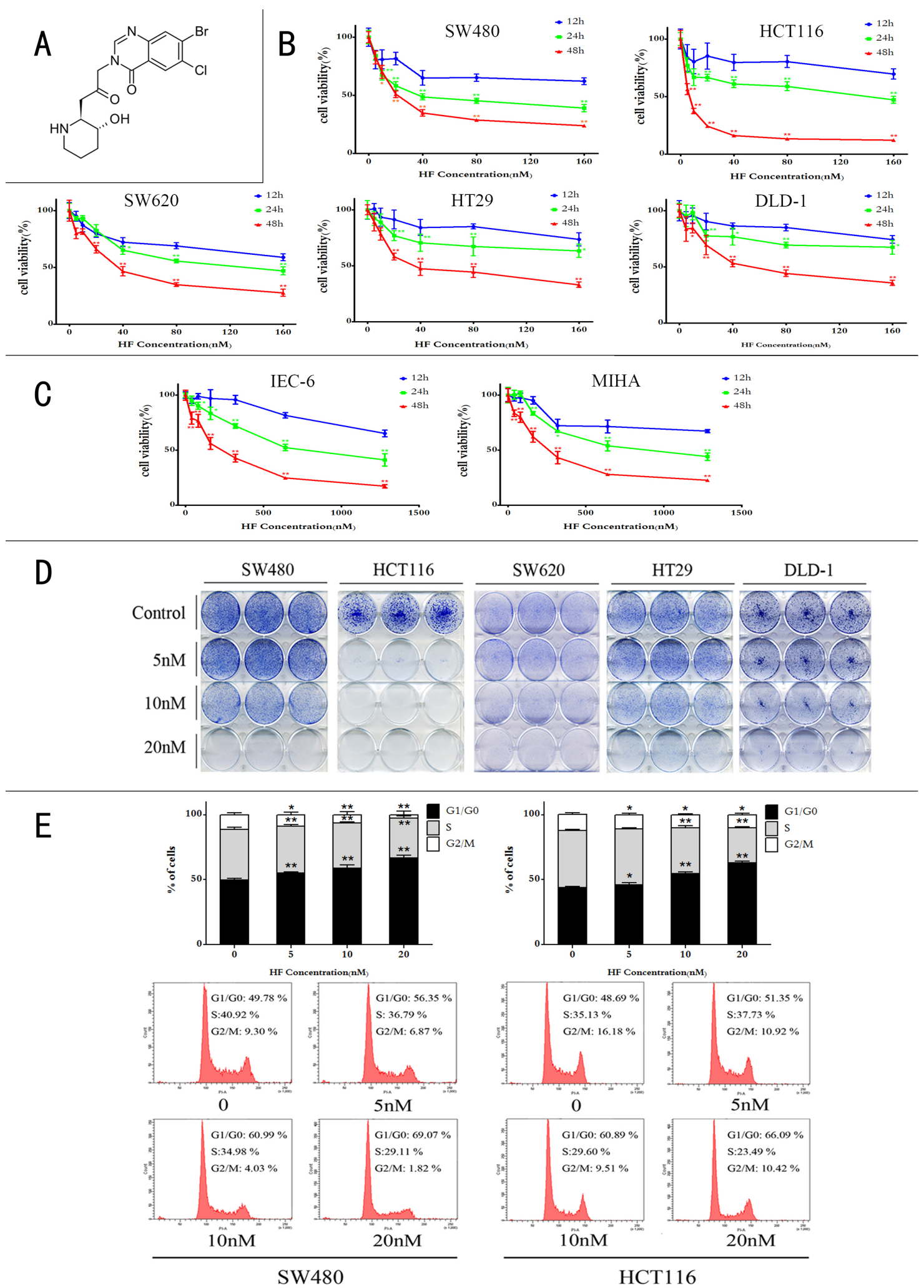

Figure 1: Halofuginone inhibits colorectal cancer cell proliferation. A. Chemical structure of halofuginone. B. MTT assay of five CRC cell lines (SW480, HCT116, SW620, HT29 and DLD-1) treated with increasing concentrations of HF in a time course (12 h, 24 $\mathrm{h}$ and $48 \mathrm{~h}) . * P<0.05, * * P<0.01$, compared with $12 \mathrm{~h}$ at the same concentration. C. MTT assay of non-transformed rat small intestinal epithelial cell line IEC-6 and human non-tumorigenic liver cell line MIHA treated with increasing concentrations of HF in a time course (12 h, $24 \mathrm{~h}$ and $48 \mathrm{~h}$ ). D. Colony formation assay of CRC cell lines (SW480, HCT116, SW620, HT29 and DLD-1) treated with 0, 5, 10 and 20 nM of HF. E. A flow cytometry analysis of SW480 and HCT116 treated with 0, 5, 10 and $20 \mathrm{nM}$ of HF for $12 \mathrm{~h}$ inducing cell cycle arrest in $\mathrm{G} 1 / \mathrm{G} 0$ phase. $* P<0.05, * * P<0.01$, compared with control group. 
A
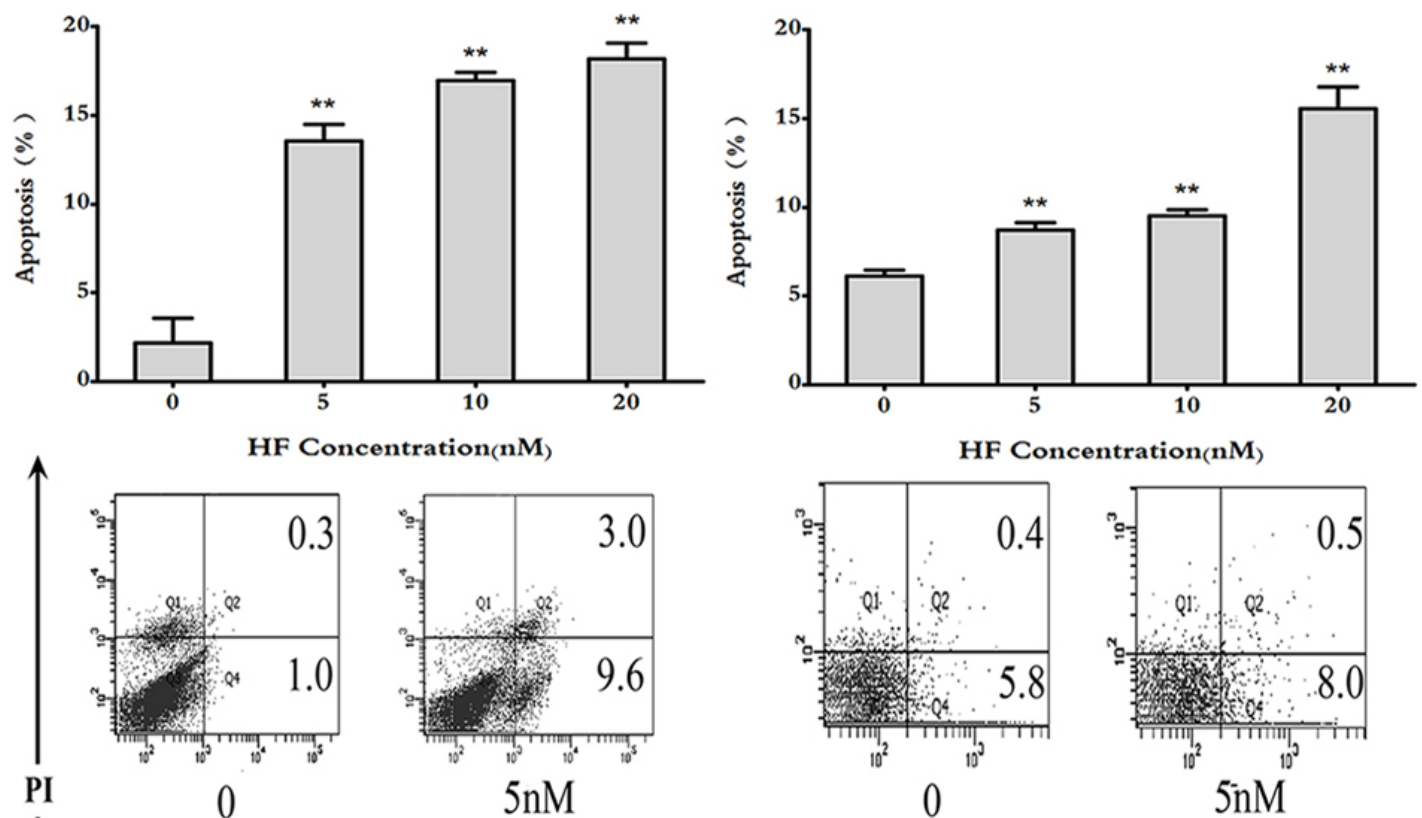

HF Concentration(nM)

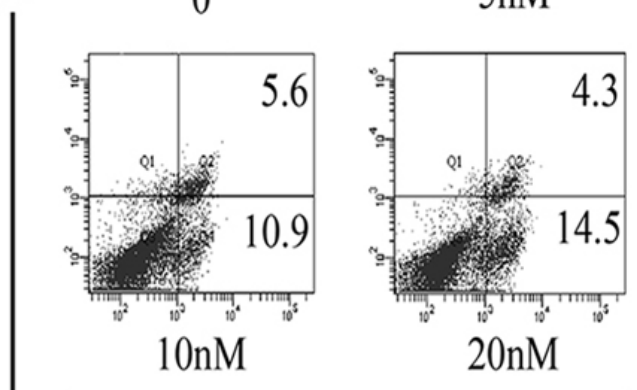

SW480
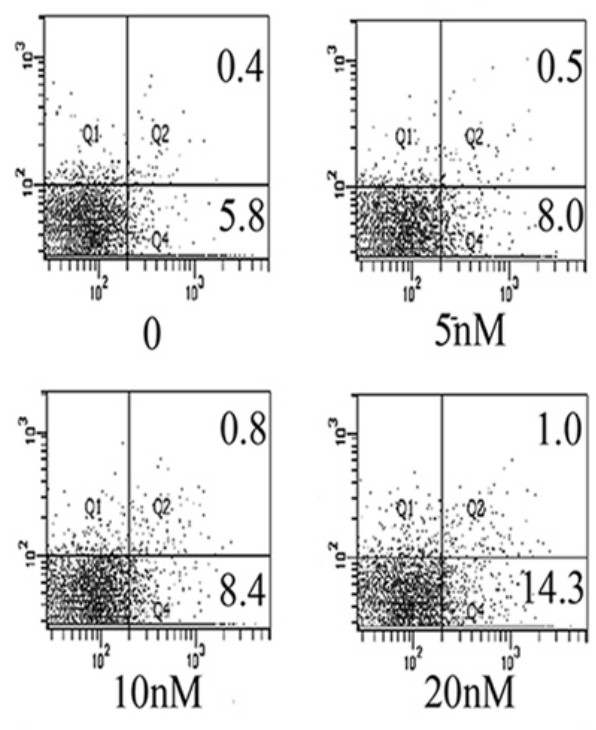

HCT116

Annexin V

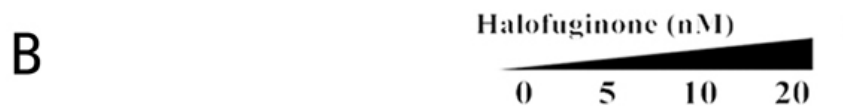

Halofuginone (n.M)

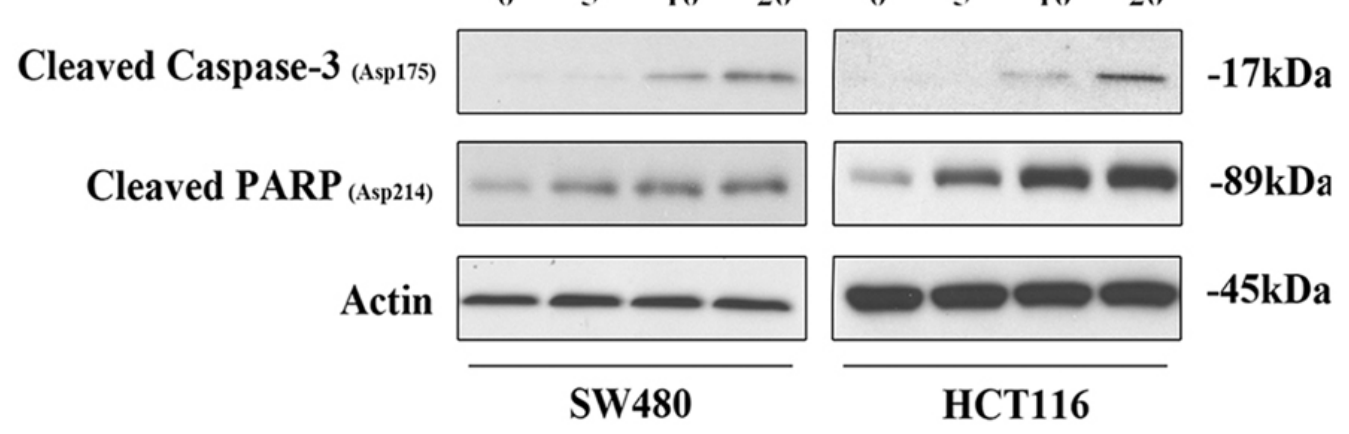

Figure 2: Halofuginone induces cell apoptosis. A. The bar chart shows the percentage of apoptotic cells in SW480 and HCT116 cell lines treated with $0,5,10$ and $20 \mathrm{nM}$ of $\mathrm{HF}$ (upper panel), and the representative flow cytometry annexin V-PI data (lower panel). $* P$ $<0.05,{ }^{*} P<0.01$, compared with control group. B. Protein expressions of cleaved Caspase-3 and cleaved PARP in SW480 and HCT116 cell lines treated with $0,5,10$ and $20 \mathrm{nM}$ of $\mathrm{HF}$. 
ROS formation in CRC cells. After HF treatment for 12 $\mathrm{h}$, CRC cells produced more ROS than control group (Figure 3A). In particular, $20 \mathrm{nM} \mathrm{HF}$ pronouncedly elevated ROS levels in both SW480 and HCT116 cell lines. Co-treatment with N-Acetyl-L-cysteine (NAC) fully reversed the HF-induced increase in ROS and cell death (Figures S2 and S3). To further evaluate mitochondriaderived ROS production, we detected mitochondrial marker voltage-dependent anion channel (VDAC) located on the outer mitochondrial membrane and found that HF treatment markedly augmented VDAC protein levels (Figure 3B). Based on the ROS results, we also measured the reducing power NADPH production and observed the increased ratios of $\left[\mathrm{NADP}^{+}\right] /[\mathrm{NADPH}]$ in both $\mathrm{SW} 480$ and HCT116 cell lines in agreement with elevated ROS levels (Figure 3C). To further identify which metabolic enzyme generating NADPH is affected by HF treatment, glucose-6-phosphate dehydrogenase (G6PD, EC: 1.1.1.49) and 6-phosphogluconate dehydrogenase (PGD, EC: 1.1.1.44) in oxidative branch of PPP, malic enzyme (ME1, EC: 1.1.1.40) in pyruvate metabolism and isocitrate dehydrogenase (IDH1, EC: 1.1.1.42) in tricarboxylic acid (TCA) cycle were examined. Surprisingly, only G6PD was pronouncedly downregulated, which could attenuate the power of scavenging ROS (Figure 3D and Figure S4).

\section{Halofuginone downregulates Akt/mTORC1 signaling pathway, slows glycolysis and inhibits lipid biosynthesis}

As mentioned above, HF inhibited cell proliferation, induced ROS and apoptosis. We also reasoned how HF treatment regulates metabolic pathways to exert anticancer activity against CRC. Given that Akt/mTORC1 pathway plays a central role in the activation of Warburg effect for cancer cell survival $[6,23]$, we further asked whether HF could repress aerobic glycolysis via Akt/mTORC1 signaling pathway in CRC cells. After treatment for 12 $\mathrm{h}$, $\mathrm{HF}$ resulted in decreased phosphorylation of Akt, mTORC1 and p70S6K while increased phosphorylation of 4EBP1 in a dose-dependent manner (Figure 4A). To further delineate glycolytic flux and glucose-derived TCA cycle flux in CRC cells, we used $\left[\mathrm{U}_{-}{ }^{13} \mathrm{C}_{6}\right]$-glucose as an isotopic tracer in feeding cancer cells with or without $\mathrm{HF}$ treatment for $12 \mathrm{~h}$. Metabolomics in combination with isotope labeling technique by using ultrahighperformance liquid chromatography tandem mass spectrometry revealed reduced intermediate metabolites in glycolysis (Figure 4B). To further test which glycolytic enzyme is affected by HF treatment, we assayed protein expressions of hexokinase 2 (HK-II), M2 isoform of pyruvate kinase (PKM2), pyruvate dehydrogenase (PDH) and lactate dehydrogenase A (LDHA). Intriguingly, only sharp decrease of HK-II was observed (Figure 4C and Figure S5). The isotopic patterns of intermediate metabolites in TCA cycle was also analyzed by using gas chromatography mass spectrometry. As a result, the reduced intermediate metabolites in TCA cycle were observed upon HF treatment in HCT116 cells. Scrambling of carbon from glucose was detected in citrate, fumarate and malate with different scrambled labeling patterns (e.g., $m+2$ and $m+4$ isotopologues in Figure 4D). Interestingly, the $\mathrm{m}+2$ isotopologues of these three metabolites are the most abundant in the isotopologues of each metabolite because acetyl-Coenzyme A labelled with two ${ }^{13} \mathrm{C}$ enters TCA cycle from glycolytic shunt. Due to a broad effect correlated with glucose metabolism, we further investigated the possibility of glucose uptake altered by HF treatment. As a result, glucose transporter GLUT1 was found to be downregulated in CRC cells upon HF treatment (Figure S6), indicating that glucose uptake was also inhibited as an upstream event. In addition, it is well known that glucose is one of the main carbon sources for lipid biosynthesis which could be regulated by $\mathrm{p} 70 \mathrm{~S} 6 \mathrm{~K}$. Thus, we further profiled lipid species of cancer cells under influence of HF treatment by using ultrahigh-performance liquid chromatography Orbitrap XL mass spectrometry. As a result, up to 49 lipid species in HCT116 cells covering phosphatidylcholine, ceramide, sphingomyelin, phosphatidylglycerol, phosphatidylethanolamine, phosphatidylserine, phosphatidylinositol and phosphatidic acid were downregulated by HF treatment (Figure S7). All of the lipids were tentatively identified by highly accurate masses with mass error of less than $3 \mathrm{ppm}$ in high resolution mass spectrometry by searching against METLIN Metabolite Database. The lipid profiling was consistent with lower expression of fatty acid synthase (FAS) which is an enzyme encoded by the FASN gene in human (Figure S8).

\section{Halofuginone treatment retards tumor growth in xenograft-bearing nude mice}

Next, we tested the ability of HF to retard tumor growth in vivo. Nude mice were subcutaneously injected with HCT116 cells and on $5^{\text {th }}$ day after tumor inoculation the mice daily received saline or $\mathrm{HF}(0.1 \mathrm{mg} / \mathrm{kg} /$ day $)$ intraperitoneally for 14 consecutive days. After 14 days of administration, the animals were euthanized to compare tumor burden between vehicle (saline treatment) and HFtreated groups. The HF treatment significantly retarded tumor growth in nude mice as measured by tumor volume while body weight was unaffected (Figures 5A and 5B). Moreover, tumor weight and size in HF-treated group are markedly less than the vehicle group (Figures $5 \mathrm{C}$, $5 \mathrm{D}$ and $5 \mathrm{E}$ ). To further define the mechanism of tumor growth inhibition in vivo, the TUNEL apoptotic assay was performed on tumor tissues. As can be seen in Figure 5F, TUNEL staining showed that HF treatment induced significant apoptosis in tumors, as shown by the stronger red fluorescence labeled anti-BrdU monoclonal antibody. 
A

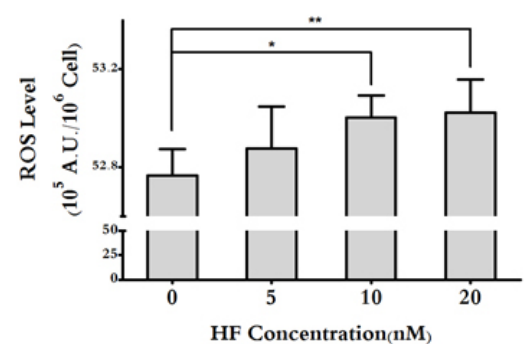

HCT116

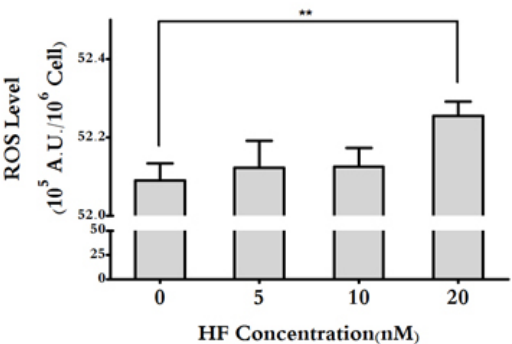

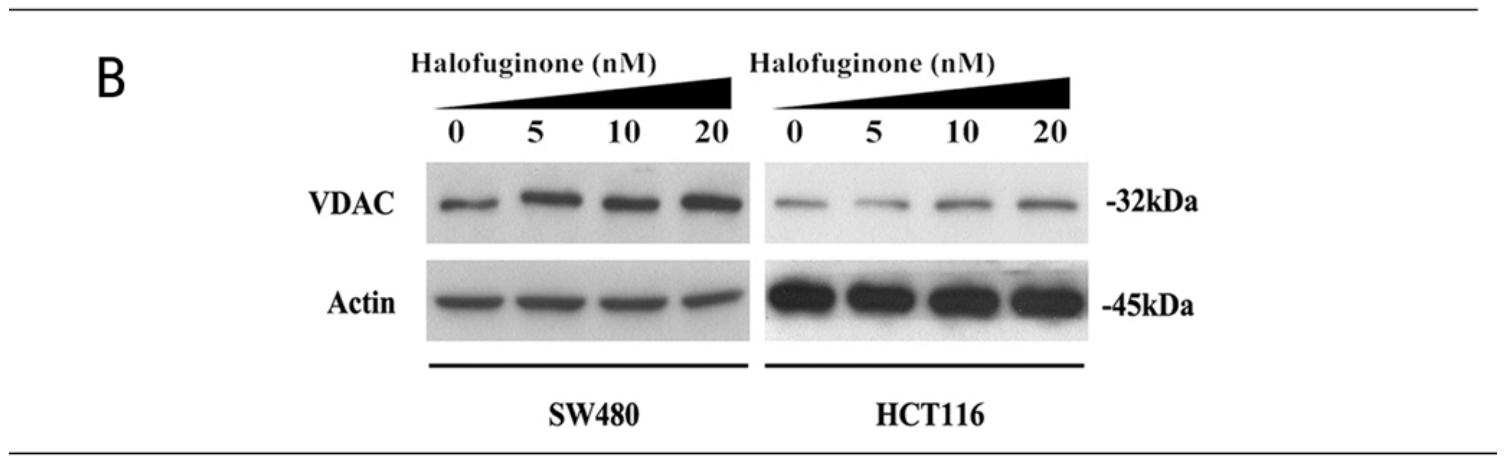

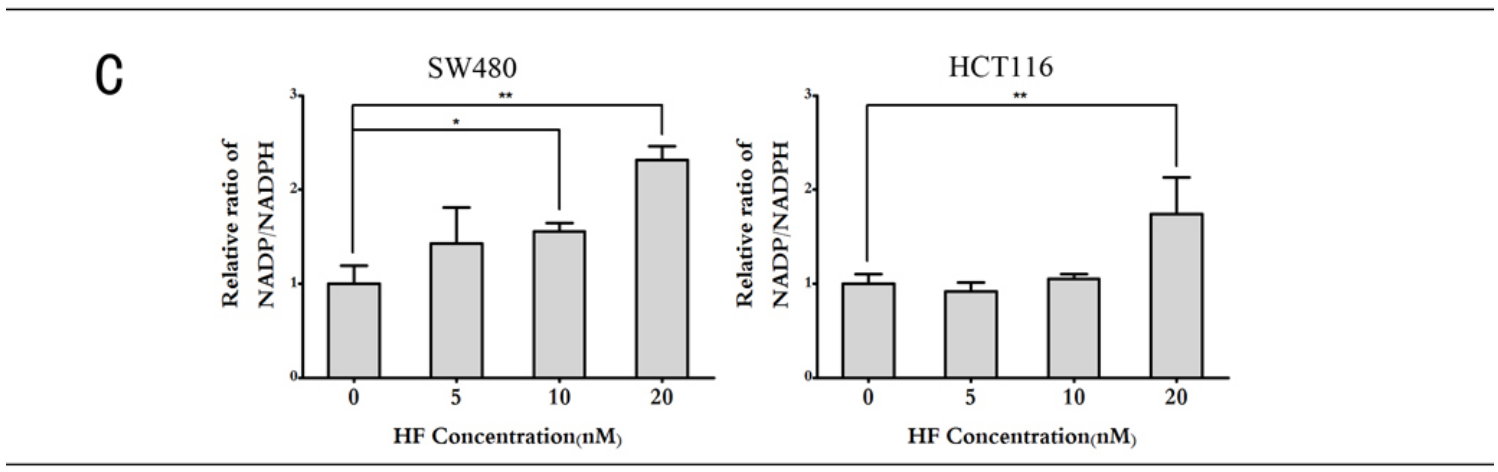

D

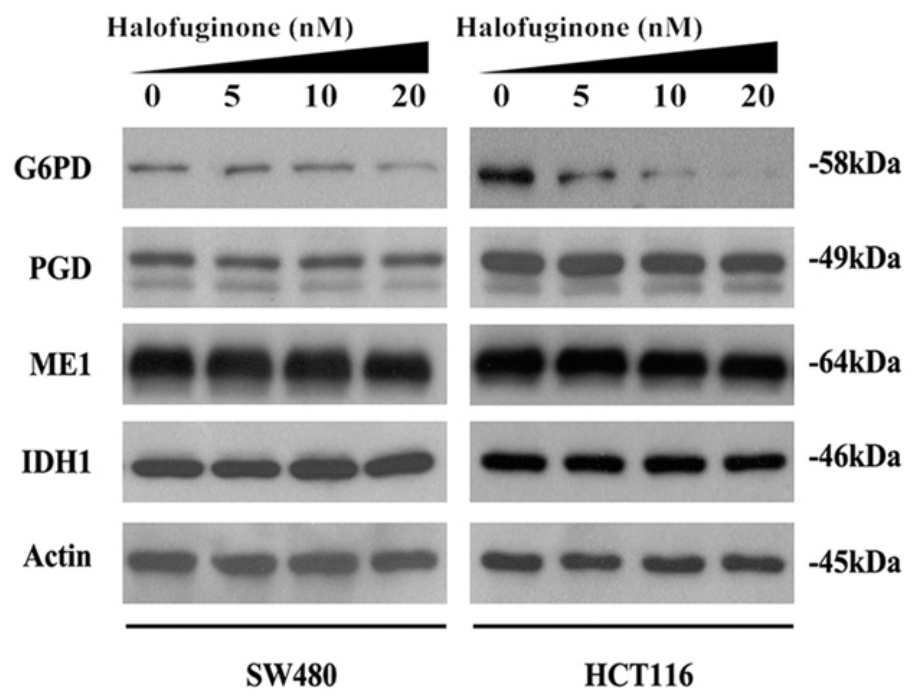

Figure 3: Halofuginone enhances ROS levels while reduces NADPH production. A. ROS levels in SW480 and HCT116 cell lines treated with $0,5,10,20 \mathrm{nM}$ of $\mathrm{HF}$. $* P<0.05, * * P<0.01$, compared with control group. B. Protein expression of mitochondrial marker VDAC in SW480 and HCT116 cell lines treated with 0, 5, 10, $20 \mathrm{nM}$ of HF. C. Relative ratios of [NADP $\left.{ }^{+}\right] /[\mathrm{NADPH}]$ in SW480 and HCT116 cell lines treated with $0,5,10,20 \mathrm{nM}$ of HF. ${ }^{*} P<0.05,{ }^{* *} P<0.01$, compared with control group. D. Protein expression of G6PD, PGD, ME1 and IDH1 in SW480 and HCT116 cell lines treated with 0, 5, 10, $20 \mathrm{nM}$ of HF (G6PD: glucose-6-phosphate dehydrogenase, PGD: 6-phosphogluconate dehydrogenase, ME1: malic enzyme, IDH1: isocitrate dehydrogenase). 

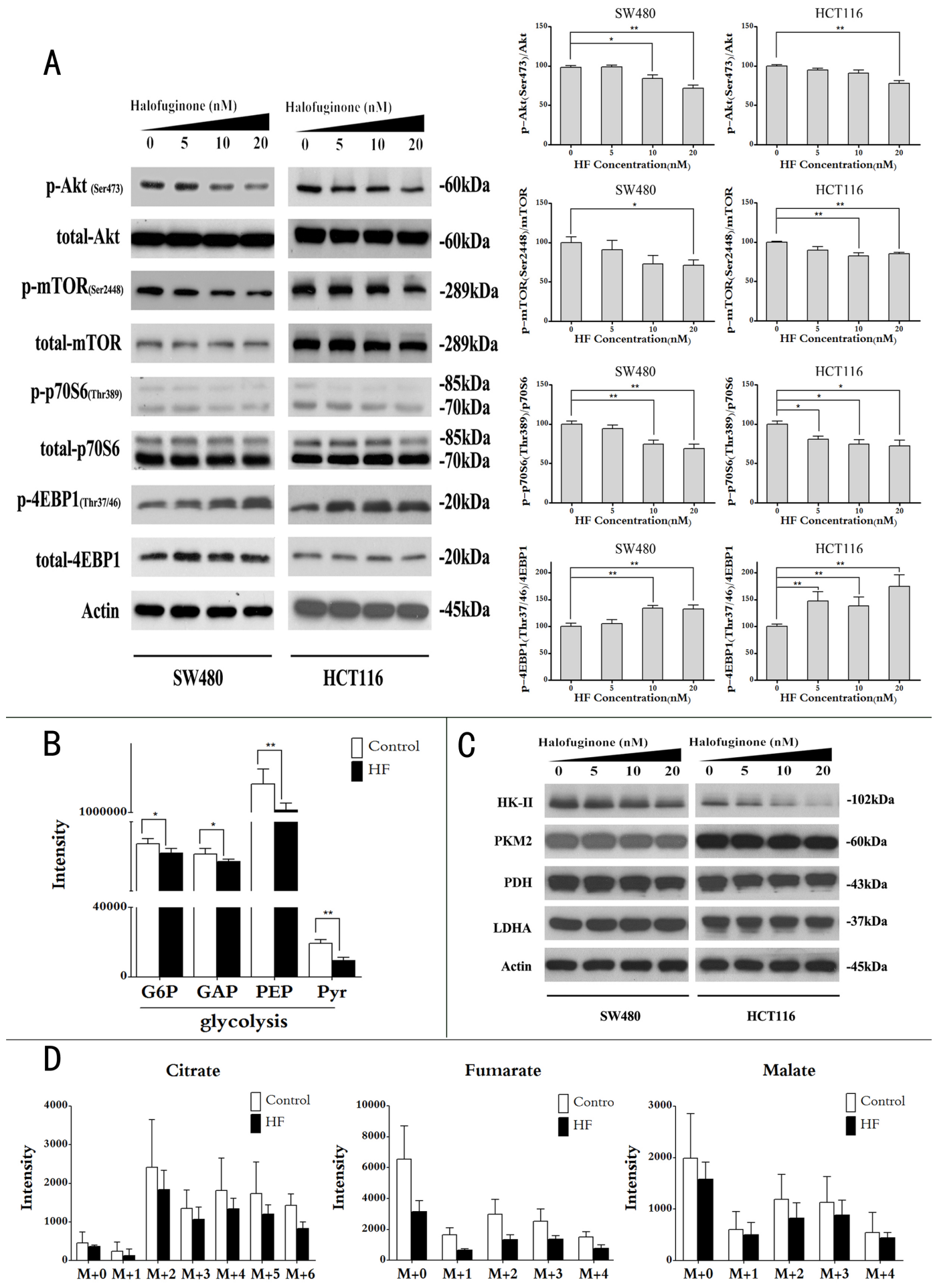

Figure 4: Halofuginone suppresses Akt/mTORC1 signaling pathway and slows glycolytic flux and glucose-derived TCA cycle flux. A. Protein expressions of phosphorylation of Akt, mTORC1, p70S6 and 4EBP1 (left panel); quantitative analysis of protein expressions (right panel) in SW480 and HCT116 upon HF treatment in a dose-dependent manner for $12 \mathrm{~h} . * P<0.05,{ }^{* * *} P<0.01$, compared with control group. B. Uniformly ${ }^{13} \mathrm{C}$-labeled glucose feeding cancer cells for intermediate metabolites in glycolysis by using UPLC-MS/MS (G6P: glucose-6-phosphate, GAP: glyceraldehyde-3-phosphate, PEP: phosphoenolpyruvate, Pyr: pyruvate). The results shown are means \pm SEM, $n=5$. ${ }^{*} P<0.05, * * P<0.01$, compared with control group. C. Protein expressions of HK-II, PKM2, PDH and LDHA by Western blot (HK-II: hexokinase-2, PKM2: M2 isoform of pyruvate kinase, PDH: pyruvate dehydrogenase, LDHA: lactate dehydrogenase A). D. The GC/MS analysis of $\left[\mathrm{U}^{-13} \mathrm{C}_{6}\right]$-glucose contribution to citrate, fumarate and malate synthesis in $\mathrm{HCT} 116$ cell with or without $\mathrm{HF}$ treatment. All GC/MS data were corrected for natural abundance isotopic contribution and normalized to cell number and internal standard 4-chloro-DL-phenylalanine. The results shown are means $\pm \mathrm{SEM}, n=5$. 


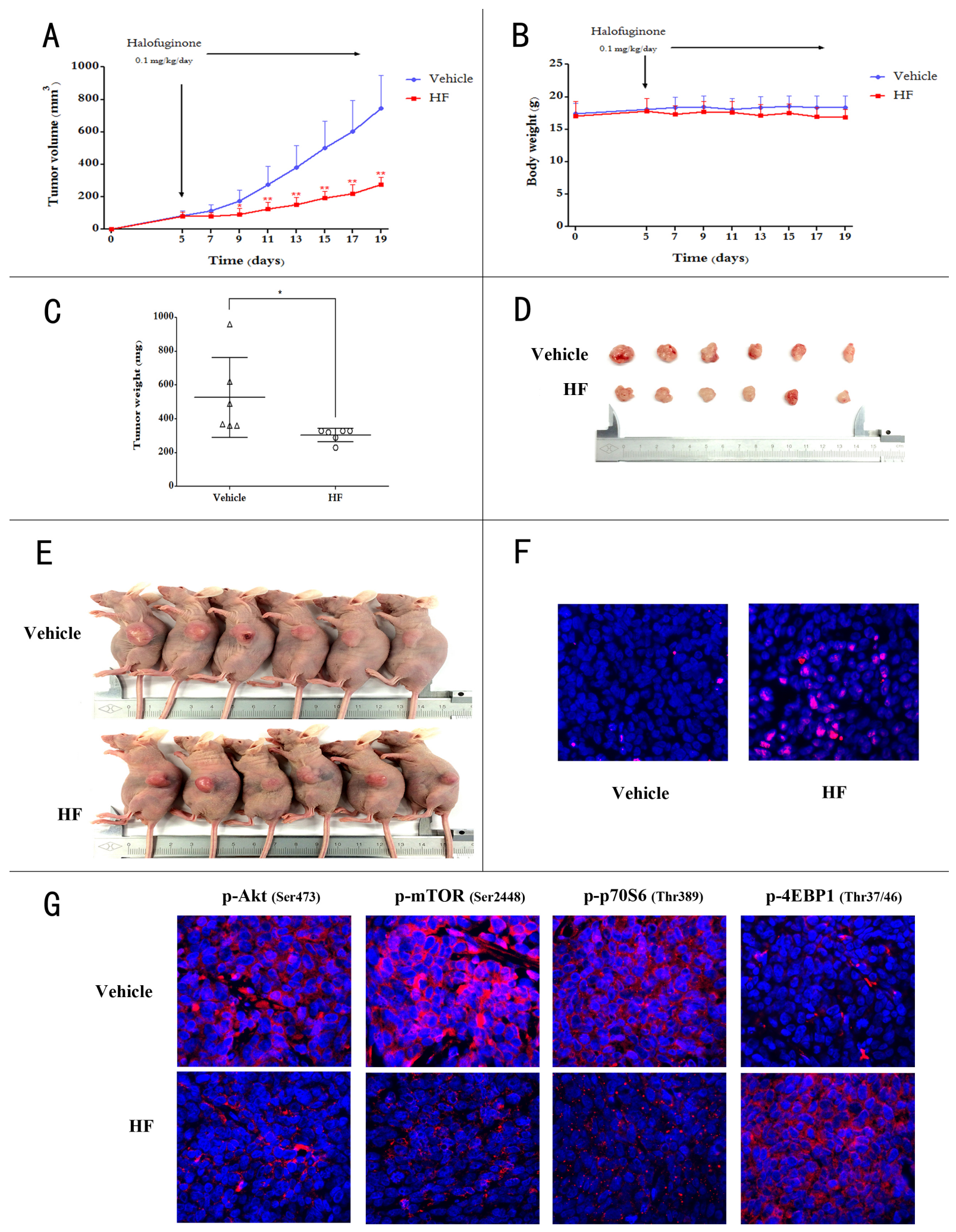

Figure 5: Halofuginone retards tumor growth in xenograft-bearing BALB/c nude mice. A. Tumor volumes between HF-treated and vehicle group during treatment for 14 days. $* P<0.05, * * P<0.01$, compared with vehicle group. B. Change in body weight between HF-treated and vehicle group. C. Change in tumor weight between HF-treated and vehicle group. $* P<0.05$ compared with vehicle group. D. The xenograft tumors were dissected and measured after two weeks and shown. E. Photos of all of the animals. F. TUNEL staining of paraffin embedded 5 micron think tumor sections of HCT116 xenograft-bearing nude mice. G. The decreased p-Akt, p-mTORC1, p-p70S6K and increased p-4EBP1 are shown in the immunofluorescence staining. 
We also validated the Akt/mTORC1 signaling pathway in vivo upon $\mathrm{HF}$ treatment. The visualization indicated decreased staining of phosphorylated Akt, mTORC1 and p70S6K, and increased staining of phosphorylated 4EBP1 in HF treated group compared to the vehicle group (Figure $5 \mathrm{G}$ and Figure $\mathrm{S} 9$ ), in line with the in vitro results.

\section{DISCUSSION}

Colorectal cancer (CRC) is a malignant neoplasm affecting the lower gastrointestinal tract, awaiting novel drugs for selectively killing CRC [24]. In the functional examination of this study, we found that HF has high toxicity to $\mathrm{CRC}$ cells with the lowest concentration of 5.82 $\mathrm{nM}$ as $\mathrm{IC}_{50}$ in HCT116 cells after 48 h-treatment. But on the other hand, HF displays relatively low toxicity to the tested non-tumorigenic intestinal epithelial cells or liver cells by MTT assay. This compound exerted anticancer activity through inhibition of cancer cell proliferation, induction of ROS and apoptosis in vitro, in line with the effect of $\mathrm{HF}$ in breast cancer [25]. In CRC cells, HFinduced cell death is rescued by the antioxidant NAC. Additionally, the augmented expression of mitochondrial marker VDAC in SW480 and HCT116 cell lines indicated that the elevated mitochondria-derived ROS production might contribute to cell apoptosis, as previously reported [26-29]. As expected, the reducing power NADPH significantly decreased in SW480 and HCT116 cell lines upon HF treatment, which might be at least partially caused by the inhibition of G6PD [30]. G6PD, as the first and rate-limiting enzyme of the PPP, can be inactivated to reduce NADPH production and biosynthesis, like tumor suppressor gene $p 53$ [31]. Therefore, HF can also dampen oxidative branch of PPP which is stimulated by p70S6K [7]. In this regard, how HF guards glucose metabolism should be further interrogated for a better understanding of the underlying metabolic mechanism.

$\mathrm{Akt} / \mathrm{mTORC} 1$ pathway is a crucial player in CRC development and some of the inhibitors of mTORC1 has been tested in clinical trials [32], suggesting that inhibition of Akt/mTORC1 would be an attractive target in CRC therapy. As one of the main signaling pathways, Akt/mTORC1 signaling triggers Warburg effect and mitochondrial dysfunction in cancer cells [33-35]. In other words, oncogenic processes give rise to rewired metabolism focused upon Warburg effect and

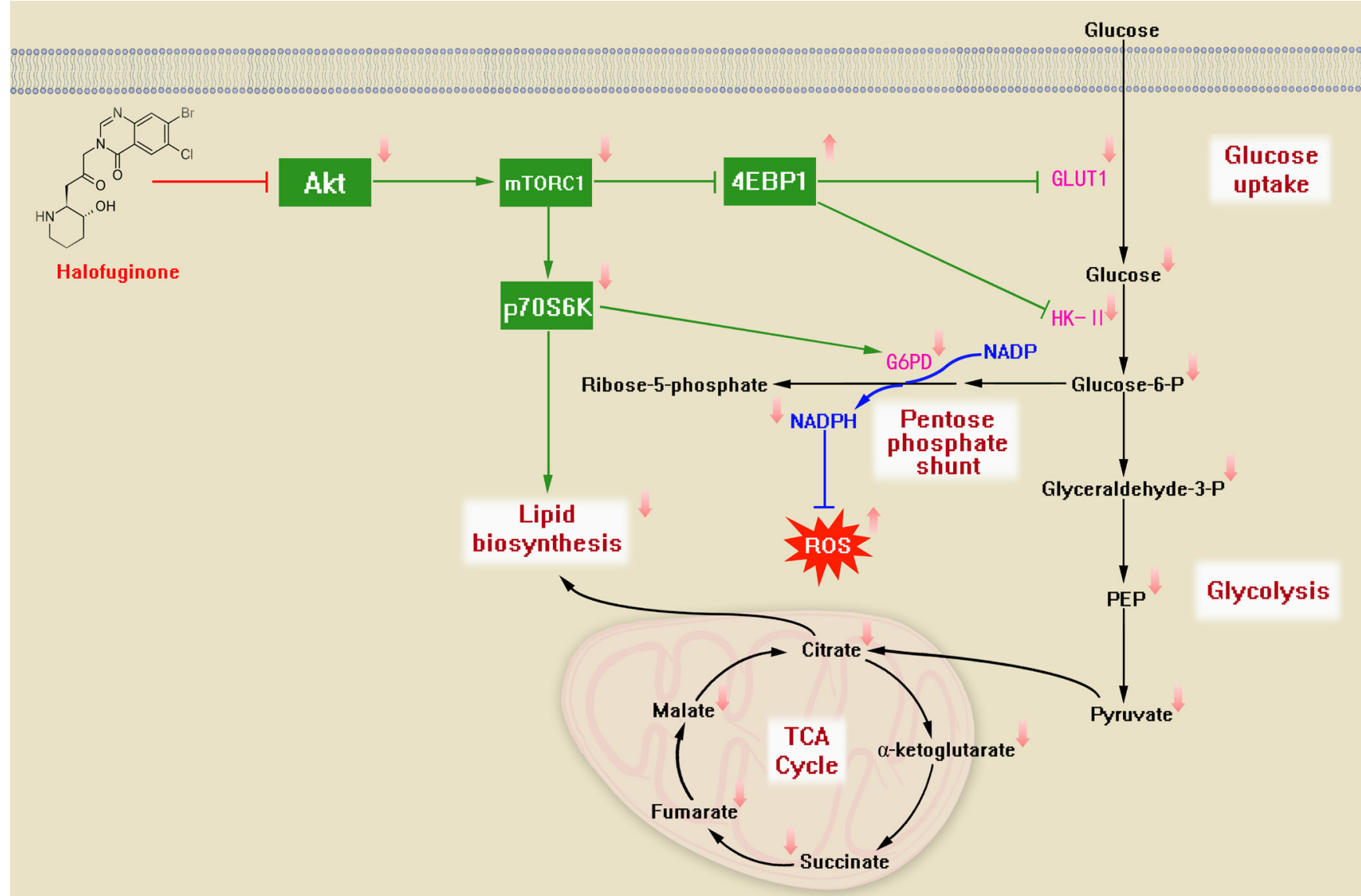

Figure 6: The proposed metabolic mechanism modulated by HF treatment in CRC cells. HF can downregulate Akt/ mTORC1 signaling pathway and repress Warburg effect, particularly, inhibit GLUT1 and HK-II through activation of 4EBP1. Accordingly, the glycolytic flux and TCA cycle flux are downregulated. Meanwhile, HF can inhibit the downstream of mTORC1 p70S6K for dampening PPP and lipid biosynthesis. 
the pentose shunt, providing higher levels of reducing activities for cancer cell proliferation, like oncogenic effects mediated by Nrf2, TAp73 [36, 37]. In CRC, glucose consumption and lipid metabolism have also been promoted by oncogenic alterations for tumor growth $[38,39]$. In this regard, the anticancer activities of ideal drugs are expected to inhibit oncogenic effects as well as suppress glucose metabolism and lipid biosynthesis in cancer cells. Therefore, we further investigated how HF treatment modulates Warburg effect via Akt/ mTORC1 signaling pathway. Of particular interest is that HF could downregulate Akt/mTORC1 pathway in both SW480 and HCT116 cell lines. More importantly, the downstream effectors of mTORC1 were also modulated by $\mathrm{HF}$ treatment in CRC cell lines. The p70S6K is one of the effectors of mTORC1, which can activate PPP; while another effector 4EBP1 inhibits glucose uptake and glycolysis. Phosphorylation of p70S6K was downregulated while phosphorylation of 4EBP1 was upregulated, coupling with slower glycolytic rate, suggesting that HF exerts anti-CRC through suppression of Warburg effect. The reduced glucose-derived TCA cycle flux suggested that carbon source from glucose has been significantly inhibited by HF treatment. Surprisingly, glucose transporter GLUT1 and the enzyme HK-II which catalyzes the first committed step of glycolysis, were pronouncedly inhibited by HF treatment in a dosedependent manner, revealing that the upstream events of glucose metabolism could be mediated by Akt/mTORC1 signaling upon HF treatment. Regarding the growing evidence that HK-II mediates Warburg effect [40] and HKII is phosphorylated by Akt associated with mitochondria [33], HF treatment in CRC could repress Warburg effect and might also disturb mitochondrial metabolism. An intriguing study shows that tumor initiation and maintenance of lung cancer and breast cancer can be inhibited by ablating HK-II using conditional knockout mice [41], postulating that HK-II could be a key target for HF in treating cancers. Therefore, how HF treatment exactly modulates glucose uptake and HK-II in CRC still needs to be further explored. In addition, lipid biosynthesis mediated by $\mathrm{p} 70 \mathrm{~S} 6 \mathrm{~K}$ activity in Akt/mTORC1 pathway was also found to be downregulated upon HF treatment in CRC cells. Indeed, lipid biosynthesis or lipid droplet formation plays a crucial role in cell proliferation and tumor growth [42-44], which tightly links to mTOR signaling [45-47]. In short, HF could downregulate p70S6K activity for suppression of oxidative PPP and lipid biosynthesis. Together, we propose the metabolic mechanism in CRC cells treated with HF for its anticancer activity (Figure 6).

Inhibitory effects of HF on tumor growth were also validated in xenograft-bearing nude mice. The Akt/mTORC1 signaling pathway was confirmed as the metabolic mechanism of this compound in CRC. Notably, in the animal model, there was no significant change in body weight in HF-treated mice compared to vehicle group, indicating that HF exerts low toxicity to normal cells which was also demonstrated by MTT assay in IEC6 and MIHA cell lines. In recent studies, HF was found to inhibit phosphorylation of Smad3 via PI3K/Akt and MAPK/ERK pathways in muscle cells [48], and HF can block TGF- $\beta$ signaling for inhibition of the establishment and progression of melanoma bone metastases [19]. These reports indicate that the inhibition of Akt/mTORC1 signaling would not be the sole pathway functioned by HF. Nonetheless, a highlight of our findings with HF was its activity to inhibit cell proliferation and retard tumor growth both in vitro and in vivo through metabolic transformation involving the Akt/mTORC1 pathway. Thereby, the Akt/mTORC1 signaling pathway altering glucose metabolism and lipid biosynthesis could be targeted by HF treatment in CRC.

In summary, $\mathrm{HF}$ was used to treat CRC for the first time in cells and animal models. The Akt/mTORC1 signaling pathway coupling with metabolic pathways was elucidated to indicate that HF inhibits cell proliferation and induces apoptosis, at least partially due to, the inhibition of Akt/mTORC1. Particularly, GLUT1 and HK-II were found to be markedly inhibited in a dose-dependent manner, which might be associated with metabolic reprogramming modulated by HF treatment. Furthermore, the experiments in nude mice inoculated with human CRC cells validated the therapeutic effect of HF, providing direct evidence to support our notion that HF exerts anticancer activity via Akt/mTORC1 signaling pathway. In conclusion, our study reveals potential therapy of $\mathrm{HF}$ against CRC.

\section{MATERIALS AND METHODS}

\section{Chemicals and reagents}

Halofuginone hydrobromide,
7'-dichlorodihydrofluorescin diacetate (DCFH-DA),
Collagenase A, Dnase I, HPLC-grade acetonitrile, HPLC-
grade methanol, HPLC-grade isopropanol, Methyl
tertbutyl ether (MTBE), Ammonium acetate, N-Acetyl-
L-cysteine, acetic acid, Dulbecco's Modified Eagle's
Medium without glucose, L-glutamine, phenol red, sodium
pyruvate and sodium bicarbonate (DMEM, D5030) and
Pierce (R) BCA Protein Assay Kit and [NADP ${ }^{+}$/[NADPH]
Quantification Kit were obtained from Sigma-Aldrich
(Munich, Germany). Rat EGF was purchased from Pepro
Tech (Rocky Hill, USA). [U- ${ }^{13} \mathrm{C}_{6}$ ]-glucose was purchased
from Cambridge Isotope Laboratories (Tewksbury, USA).
FITC Annexin V Apoptosis Detection Kit I was obtained
from BD Bioscience (USA). Dialyzed Fetal Bovine Serum
(US Origin SH30079.03) was purchased from HyClone
(USA). In situ BrdU-red DNA fragmentation (TUNEL)
assay kit (ab66110) was obtained from Abcam.




\section{Cell culture}

HCT116, SW480, SW620, HT29, DLD-1, IEC-6 and MIHA were purchased from American Type Culture Collection (Manassas, USA). Cells were cultured in DMEM supplemented with $10 \%$ FBS in a humidified atmosphere containing $10 \% \mathrm{CO}_{2}$ and $90 \%$ air at $37^{\circ} \mathrm{C}$. The medium was changed every three days, and cells were passaged using $0.05 \%$ trypsin/EDTA.

\section{MTT assay}

The effect of HF on proliferation and viability of CRC cell lines and non-tumorigenic cell lines was determined by the 3-(4,5-dimethylthiazol-2-yl)-2,5diphenyltetrazolium bromide (MTT) uptake method. Briefly, the cells $(5,000$ per well) were seeded in 96-well plates 24h prior to HF treatment. The effect of HF in CRC cell line proliferation was determined in different dosages and time points. Independent experiments were performed in triplicate.

\section{Colony formation assay}

CRC cell lines were seeded in 6-well plates at a density of $1 \times 10^{5}$ cells per well in $2 \mathrm{~mL}$ medium. Treatment with various concentrations of HF for 12 to 16 days until individual cells formed distinctly visible colonies. Thereafter, cells were stained with $50 \%$ methanol solution of $2 \%$ Methylene Blue. After washing, plates were air dried and digital images were taken. Independent experiments were performed in triplicate.

\section{Cell cycle analysis}

The cell cycle phase distribution was determined by fluorescence-activated cell sorting (FACS) analysis of cellular DNA content. The cells were treated with different concentrations of $\mathrm{HF}$ for $12 \mathrm{~h}$ and then harvested by trypsinization and re-suspended in $200 \mu \mathrm{L}$ PBS. The cells were fixed in $800 \mu \mathrm{L}$ cold $100 \%$ ethanol, votexed, and then stored at $-20^{\circ} \mathrm{C}$ overnight. The fixed cells were washed twice with PBS, re-suspended in $500 \mu \mathrm{L}$ of PBS containing $5 \mu \mathrm{L}$ RNase $\left(10 \mu \mathrm{g} \mathrm{mL}^{-1}\right)$ and incubated for $30 \mathrm{~min}$ in $37^{\circ} \mathrm{C}$ bath. The cells were stained with $50 \mu \mathrm{L}$ propidium iodide (PI, $1 \mathrm{mg} \mathrm{mL}^{-1}$ ) for 5 to $10 \mathrm{~min}$ on ice in dark. The fluorescent signal was detected through the FL2 channel and the proportion of DNA in different phases was analyzed using ModFit LT version 3.1 (Verity Software House, Topsham).

\section{Annexin V/PI dye staining}

SW480 and HCT116 cells were seeded in 6-well plates $24 \mathrm{~h}$ prior to HF treatment at a density of $5 \times 10^{5}$ cells per well. After treated with different concentrations of HF for $12 \mathrm{~h}$, apoptotic cells were assessed using the Annexin V-fluorescein isothiocyanate (FITC) apoptosis detection kit I following the manufacturer's instructions. Triplicate independent experiments were performed.

\section{Western blot analysis}

After cells were treated with HF for $12 \mathrm{~h}$, whole cell lysates were obtained by suspending the cells in lysis buffer. Followed by centrifugation at 13,500 $\mathrm{rpm}$ for $15 \mathrm{~min}$ at $4^{\circ} \mathrm{C}$, total protein concentration was measured using Pierce(R) BCA Protein Assay Kit and 10 to $25 \mu \mathrm{g}$ of protein was separated on $10 \%$ sodium dodecylsulphate-polyacrylamide gel (SDS-PAGE) and transferred onto polyvinylidene difluoride membranes. After blocking (5\% skim milk powder in TBST, 20) for 1 $\mathrm{h}$ at room temperature, the membrane was then incubated with primary antibody overnight at $4{ }^{\circ} \mathrm{C}$. Antibodies against VDAC (D73D12), phosphor-mTOR (Ser2448), phosphor-p70S6 Kinase (Thr389), phosphor-4EBP1 (Thr37/46), phosphor-Akt (Ser473), Akt (pan) (C67E7), 4EBP1, p70S6 Kinase (49D7), mTOR (7C10), cleavedPARP, cleaved-caspase 3, GLUT1 (D3J3A), fatty acid synthase (C20G5) and $\beta$-actin were purchased from Cell Signaling Technology, Inc. (Danvers, MA). The membrane was incubated with secondary antibody for $1 \mathrm{~h}$ at room temperature. HRP-goat anti-rabbit secondary antibody was purchased from Invitrogen (Carlsbad, USA). Goat anti-mouse IgG-HRP secondary antibody was purchased from San Cruz Biotechnology (Santa Cruz, USA). All antibodies were diluted in TBS-Tween 20 containing 5\% dry milk. The immune-reactive proteins were detected by enhanced chemiluminescence (ECL) using X-ray film and ECL reagent.

\section{Quantitative analysis of mRNA levels}

Total RNA was isolate from SW480 or HCT116 cells using TRIzol reagent (Invitrogen). cDNAs were prepared by reverse transcription and quantitative polymerase chain reaction (PCR) was performed using the Quantitect SYBR green PCR Master mix (Qiagen, Valencia, CA) with 1 $\mu \mathrm{L}$ cDNA in a final volume of $10 \mu \mathrm{L}$ and the following primers at a final concentration of $1000 \mathrm{nM}$. Primers for Glut1 were 5'- TGGCATCAACGCTGTCTTCT-3' (forward) and 5'- CTAGCGCGATGGTCATGAGT-3' (reverse). Primers for G6PD were 5'TGCATGAGCCAGATAGGCTG-3' (forward) and 5'GGTAGTGGTCGATGCGGTAG-3' (reverse). Primers 
for HK-II were 5'- ACAAATTTCCGGGTCCTGCT-3' (forward) and 5'- TGAGGAGGATGCTCTCGTCCA-3' (reverse).

Amplification of Glut1, G6PD and HK-II cDNAs was performed using the LightCycler 2000 instrument (Roche, Indianapolis, IN). The cycling conditions comprised a denaturation step for 15 minutes at $95^{\circ} \mathrm{C}$, followed by 40 cycles of denaturation $\left(95^{\circ} \mathrm{C}\right.$ for 15 seconds), annealing $\left(59^{\circ} \mathrm{C}\right.$ for 20 seconds), and extension $\left(72^{\circ} \mathrm{C}\right.$ for 15 seconds). After amplification, a melting curve analysis was performed with denaturation at $95^{\circ} \mathrm{C}$ for 5 seconds, then continuous fluorescence measurement from $70^{\circ} \mathrm{C}$ to $95^{\circ} \mathrm{C}$ at $0.1^{\circ} \mathrm{C} /$ second. Each sample was amplified in duplicate.

\section{Measurement of cellular ROS levels}

Intracellular ROS levels were assayed using DCFHDA as described previously [49]. Briefly, following exposure to different concentrations of HF for $12 \mathrm{~h}, \mathrm{CRC}$ cells were counted to determine live cell concentration. Cells were then harvested by centrifugation at $250 \mathrm{~g}$ for $5 \mathrm{~min}$ and washed once with washing buffer. The cell pellet was then re-suspended in DMEM containing 20 $\mu \mathrm{M}$ DCFH-DA. Cell suspensions were then incubated for $30 \mathrm{~min}$ at $37^{\circ} \mathrm{C}$ under constant agitation. After washing twice with washing buffer, the cells were resuspended in $1 \mathrm{~mL}$ of washing buffer (PBS containing $10 \mathrm{mM}$ dextrose). Fluorescence was recorded using a 96-well plate reader operating at an excitation/emission wavelength of $485 \mathrm{~nm} / 530 \mathrm{~nm}$ (EnVision 2104 Multilabel Reader, PerkinElmer). Mean fluorescence values of DCFH-DA-loaded cells were corrected by subtracting the autofluorescence background.

\section{Measurement of [NADP+]/[NADPH] Ratio}

$\left[\mathrm{NADP}^{+}\right] /[\mathrm{NADPH}]$ ratios in $\mathrm{CRC}$ cell lines treated with $\mathrm{HF}$ were measured according to the protocol of $\left[\mathrm{NADP}^{+}\right] /[\mathrm{NADPH}]$ Quantification Kit (MAK038, Sigma). According to the NADPH standards, the concentration of NADP ${ }_{\text {total }}$ or NADPH can be expressed in pmole per $10^{6}$ cells. The ratio of $\left[\mathrm{NADP}^{+}\right] /[\mathrm{NADPH}]$ was calculated by $\left(\left[\mathrm{NADP}_{\text {total }}\right]-[\mathrm{NADPH}]\right) /[\mathrm{NADPH}]$.

\section{Xenograft studies}

$\mathrm{BALB} / \mathrm{c}$ nude mice, female, 6-week old, were obtained from the Laboratory Animal Services Centre, The Chinese University of Hong Kong. Mice were kept at room temperature $23 \pm 2{ }^{\circ} \mathrm{C}$ with an alternating $12 \mathrm{~h}$ lightdark cycle, and were allowed access to food and water $\mathrm{ad}$ libitum. All of the experimental protocols were carried out with the approval of the Committee on Use of Human and
Animal Subjects in Teaching and Research of Hong Kong Baptist University and according to the Regulations of the Department of Health, Hong Kong SAR, China. HCT116 cells $\left(3 \times 10^{6}\right.$ cells $\left./ 100 \mu \mathrm{L}\right)$ were suspended in PBS and inoculated subcutaneously into the left flank of each mouse and tumor growth was monitored regularly. Once tumors were palpable, $\left(\sim 100 \mathrm{~mm}^{3}\right)$, mice were divided at random into two groups within 6 mice in each group: (i) Vehicle group, normally fed, receiving daily i.p. saline; (ii) HF group, normally fed, receiving daily i.p. HF (0.1 $\mathrm{mg} / \mathrm{kg}$ /day) dissolved in $0.9 \%$ sodium chloride solution. The tumors were measured with calipers every 2 days, and the tumor volumes were calculated by the following formula: $\mathrm{a}^{2} \times \mathrm{b} \times 0.4$, where " $\mathrm{a}$ " is the smallest diameter and " $b$ " is the diameter perpendicular to " $a$ ". Other indicators of general health, such as body weight, feeding behavior, and motor activity of each animal were also monitored. After administration of HF or saline for two weeks, the mice were euthanized, and the tumor xenografts were immediately dissected, weighted, stored and fixed.

\section{Immunofluorescence assay and TdT-mediated dUTP nick end labelling (TUNEL) assay}

Xenograft tumors were resected immediately and fixed in 10\% neutral buffered paraformaldehyde at $4{ }^{\circ} \mathrm{C}$ for $24 \mathrm{~h}$. Selected samples were embedded in paraffin, sectioned and stained with phosphor-Akt (Ser473), phosphor-mTOR (Ser2448), phosphor-p70S6 Kinase (Thr389), phosphor-4EBP1 (Thr37/46). All primary antibodies were used for dilution at 1:100. After overnight incubation at $4{ }^{\circ} \mathrm{C}$, the sections were incubated with flurochrome-conjugated secondary antibody for 1 $\mathrm{h}$ and stained with DAPI for $10 \mathrm{~min}$. The sections were then mounted with DPX mountant (Sigma, 317616) for analysis. For the TUNEL assay, sections were deparafinnized and apoptotic cells were detected using the in situ BrdU-Red DNA fragmentation (TUNEL) assay kit (Abcam) and counterstained with DAPI.

\section{Metabolic flux analysis and lipidomics}

$\left[\mathrm{U}-{ }^{13} \mathrm{C}_{6}\right]$-glucose was used to feed cancer cells for metabolic flux analysis (MFA). Ultrahigh-performance liquid chromatography tandem mass spectrometry (UPLC$\mathrm{MS} / \mathrm{MS}$ ) and gas chromatography mass spectrometry (GC/ MS) were employed for MFA. Meanwhile, ultrahighperformance liquid chromatography Orbitrap XL mass spectrometry was utilized for lipidomics analysis without labeling in cell culture. The details of metabolite extraction and chromatographic separation coupled with mass spectrometric conditions are described in the Supplementary Information. 


\section{ACKNOWLEDGMENTS}

GQC has been supported by Chongqing Science \& Technology Commission (2013CSTC-JBKY-01901), SHL has been supported by the National Natural Science Foundation of China (No. 21377106) and ZXB has been supported by RC-IRMC/11-12/02-SCM. We thank Ms. $\mathrm{H}-\mathrm{B}$ Yang for providing assistance in lipidomic analysis. We are also grateful to Ms. J-J Liu for help with editing the manuscript.

\section{CONFLICTS OF INTEREST}

There are no conflicts of interest to disclose.

\section{REFERENCES}

1. Shin A, Jung KW and Won YJ. Colorectal cancer mortality in Hong Kong of China, Japan, South Korea, and Singapore. World J Gastroenterol. 2013; 19:979-983.

2. Markowitz SD and Bertagnolli MM. Molecular origins of cancer: Molecular basis of colorectal cancer. N Engl J Med. 2009; 361:2449-2460.

3. Koseoglu S, Lu Z, Kumar C, Kirschmeier P and Zou J. AKT1, AKT2 and AKT3-dependent cell survival is cell line-specific and knockdown of all three isoforms selectively induces apoptosis in 20 human tumor cell lines. Cancer Biol Ther. 2007; 6:755-762.

4. Shaw RJ and Cantley LC. Ras, PI(3)K and mTOR signalling controls tumour cell growth. Nature. 2006; 441:424-430.

5. Zhang YJ, Dai Q, Sun DF, Xiong H, Tian XQ, Gao FH, $\mathrm{Xu} \mathrm{MH}$, Chen GQ, Han ZG and Fang JY. mTOR signaling pathway is a target for the treatment of colorectal cancer. Ann Surg Oncol. 2009; 16:2617-2628.

6. Sun Q, Chen X, Ma J, Peng H, Wang F, Zha X, Wang Y, Jing Y, Yang H, Chen R, Chang L, Zhang Y, Goto J, Onda H, Chen T, Wang MR, et al. Mammalian target of rapamycin up-regulation of pyruvate kinase isoenzyme type M2 is critical for aerobic glycolysis and tumor growth. Proc Natl Acad Sci U S A. 2011; 108:4129-4134.

7. Duvel K, Yecies JL, Menon S, Raman P, Lipovsky AI, Souza AL, Triantafellow E, Ma Q, Gorski R, Cleaver S, Vander Heiden MG, MacKeigan JP, Finan PM, Clish CB, Murphy LO and Manning BD. Activation of a metabolic gene regulatory network downstream of mTOR complex 1 . Mol Cell. 2010; 39:171-183.

8. Yalcin S, Marinkovic D, Mungamuri SK, Zhang X, Tong W, Sellers R and Ghaffari S. ROS-mediated amplification of AKT/mTOR signalling pathway leads to myeloproliferative syndrome in Foxo3(-/-) mice. EMBO J. 2010; 29:41184131.

9. Maiese K, Chong ZZ, Shang YC and Wang S. mTOR: on target for novel therapeutic strategies in the nervous system. Trends Mol Med. 2013; 19:51-60.
10. Warburg O. On the origin of cancer cells. Science. 1956; 123:309-314.

11. Vander Heiden MG, Cantley LC and Thompson CB. Understanding the Warburg effect: the metabolic requirements of cell proliferation. Science. 2009; 324:10291033.

12. Jin ML, Park SY, Kim YH, Park G and Lee SJ. Halofuginone induces the apoptosis of breast cancer cells and inhibits migration via downregulation of matrix metalloproteinase-9. Int J Oncol. 2014; 44:309-318.

13. de Figueiredo-Pontes LL, Assis PA, Santana-Lemos BA, Jacomo RH, Lima AS, Garcia AB, Thome CH, Araujo AG, Panepucci RA, Zago MA, Nagler A, Falcao RP and Rego EM. Halofuginone has anti-proliferative effects in acute promyelocytic leukemia by modulating the transforming growth factor beta signaling pathway. PLoS One. 2011; 6:e26713.

14. Pines $M$ and Nagler A. Halofuginone: a novel antifibrotic therapy. Gen Pharmacol. 1998; 30:445-450.

15. Elkin M, Ariel I, Miao HQ, Nagler A, Pines M, de-Groot $\mathrm{N}$, Hochberg A and Vlodavsky I. Inhibition of bladder carcinoma angiogenesis, stromal support, and tumor growth by halofuginone. Cancer Res. 1999; 59:4111-4118.

16. Elkin M, Reich R, Nagler A, Aingorn E, Pines M, de-Groot $\mathrm{N}$, Hochberg A and Vlodavsky I. Inhibition of matrix metalloproteinase-2 expression and bladder carcinoma metastasis by halofuginone. Clin Cancer Res. 1999; 5:19821988.

17. Gavish Z, Pinthus JH, Barak V, Ramon J, Nagler A, Eshhar $\mathrm{Z}$ and Pines M. Growth inhibition of prostate cancer xenografts by halofuginone. Prostate. 2002; 51:73-83.

18. Nagler A, Ohana M, Shibolet O, Shapira MY, Alper R, Vlodavsky I, Pines M and Ilan Y. Suppression of hepatocellular carcinoma growth in mice by the alkaloid coccidiostat halofuginone. Eur J Cancer. 2004; 40:13971403.

19. Juarez P, Mohammad KS, Yin JJ, Fournier PG, McKenna RC, Davis HW, Peng XH, Niewolna M, Javelaud D, Chirgwin JM, Mauviel A and Guise TA. Halofuginone inhibits the establishment and progression of melanoma bone metastases. Cancer Res. 2012; 72:6247-6256.

20. Sundrud MS, Koralov SB, Feuerer M, Calado DP, Kozhaya AE, Rhule-Smith A, Lefebvre RE, Unutmaz D, Mazitschek R, Waldner H, Whitman M, Keller T and Rao A. Halofuginone inhibits TH17 cell differentiation by activating the amino acid starvation response. Science. 2009; 324:1334-1338.

21. Carlson TJ, Pellerin A, Djuretic IM, Trivigno C, Koralov SB, Rao A and Sundrud MS. Halofuginone-induced amino acid starvation regulates Stat3-dependent Th17 effector function and reduces established autoimmune inflammation. J Immunol. 2014; 192:2167-2176.

22. Sabharwal SS and Schumacker PT. Mitochondrial ROS in cancer: initiators, amplifiers or an Achilles' heel? Nat Rev 
Cancer. 2014; 14:709-721.

23. Roberts DJ and Miyamoto S. Hexokinase II integrates energy metabolism and cellular protection: Akting on mitochondria and TORCing to autophagy. Cell Death Differ. 2015; 22:248-257.

24. Francipane $\mathrm{MG}$ and Lagasse E. mTOR pathway in colorectal cancer: an update. Oncotarget. 2014; 5:49-66.

25. Jin ML, Park SY, Kim YH, Park G and Lee SJ. Halofuginone induces the apoptosis of breast cancer cells and inhibits migration via downregulation of matrix metalloproteinase-9. International Journal of Oncology. 2014; 44:309-318.

26. Harris G and Schaefer KL. Reactive oxygen species induced by the compound bisphenol-a-diglycidylether cause senescence and apoptosis in colorectal cancer cell lines regardless of MDR1 or p53 status. Gastroenterology. 2008; 134:A743-A743.

27. Shin SW, Seo CY, Han H, Han JY, Jeong JS, Kwak JY and Park JI. 15d-PGJ(2) Induces Apoptosis by Reactive Oxygen Species-mediated Inactivation of Akt in Leukemia and Colorectal Cancer Cells and Shows In vivo Antitumor Activity. Clinical Cancer Research. 2009; 15:5414-5425.

28. Zhou J, Li P, Xue XF, He SB, Kuang YT, Zhao H, Chen SJ, Zhi QM and Guo XB. Salinomycin induces apoptosis in cisplatin-resistant colorectal cancer cells by accumulation of reactive oxygen species. Toxicology Letters. 2013; 222:139-145.

29. Jeong JB, Choi J, Baek SJ and Lee SH. Reactive oxygen species mediate tolfenamic acid-induced apoptosis in human colorectal cancer cells. Archives of Biochemistry and Biophysics. 2013; 537:168-175.

30. Stanton RC. Glucose-6-phosphate dehydrogenase, NADPH, and cell survival. IUBMB Life. 2012; 64:362-369.

31. Jiang $\mathrm{P}, \mathrm{Du} \mathrm{W}$, Wang $\mathrm{X}$, Mancuso A, Gao X, Wu M and Yang $\mathrm{X}$. p53 regulates biosynthesis through direct inactivation of glucose-6-phosphate dehydrogenase. Nat Cell Biol. 2011; 13:310-316.

32. Kim DD and Eng C. The promise of mTOR inhibitors in the treatment of colorectal cancer. Expert Opin Investig Drugs. 2012; 21:1775-1788.

33. Roberts DJ and Miyamoto S. Hexokinase II integrates energy metabolism and cellular protection: Akting on mitochondria and TORCing to autophagy. Cell Death Differ. 2015;22:248-57.

34. Feng $\mathrm{Z}$ and Levine AJ. The regulation of energy metabolism and the IGF-1/mTOR pathways by the 53 protein. Trends Cell Biol. 2010; 20:427-434.

35. Xu Y, Miriyala S, Fang F, Bakthavatchalu V, Noel T, Schell DM, Wang C, St Clair WH and St Clair DK. Manganese superoxide dismutase deficiency triggers mitochondrial uncoupling and the Warburg effect. Oncogene. 2014.

36. Mitsuishi Y, Taguchi K, Kawatani Y, Shibata T, Nukiwa T, Aburatani H, Yamamoto $M$ and Motohashi H. Nrf2 redirects glucose and glutamine into anabolic pathways in metabolic reprogramming. Cancer Cell. 2012; 22:66-79.

37. Du W, Jiang P, Mancuso A, Stonestrom A, Brewer MD, Minn AJ, Mak TW, Wu M and Yang X. TAp73 enhances the pentose phosphate pathway and supports cell proliferation. Nat Cell Biol. 2013; 15:991-1000.

38. Ellis BC, Graham LD and Molloy PL. CRNDE, a long noncoding RNA responsive to insulin/IGF signaling, regulates genes involved in central metabolism. Biochim Biophys Acta. 2014; 1843:372-386.

39. Wei Z, Cui L, Mei Z, Liu M and Zhang D. miR-181a mediates metabolic shift in colon cancer cells via the PTEN/ AKT pathway. FEBS Lett. 2014; 588:1773-1779.

40. Wang L, Xiong H, Wu F, Zhang Y, Wang J, Zhao L, Guo X, Chang LJ, Zhang Y, You MJ, Koochekpour S, Saleem M, Huang H, Lu J and Deng Y. Hexokinase 2-mediated Warburg effect is required for PTEN- and p53-deficiencydriven prostate cancer growth. Cell Rep. 2014; 8:14611474.

41. Patra KC, Wang Q, Bhaskar PT, Miller L, Wang Z, Wheaton W, Chandel N, Laakso M, Muller WJ, Allen EL, Jha AK, Smolen GA, Clasquin MF, Robey RB and Hay N. Hexokinase 2 is required for tumor initiation and maintenance and its systemic deletion is therapeutic in mouse models of cancer. Cancer Cell. 2013; 24:213-228.

42. Qi W, Fitchev PS, Cornwell ML, Greenberg J, Cabe M, Weber CR, Roy HK, Crawford SE and Savkovic SD. FOXO3 growth inhibition of colonic cells is dependent on intraepithelial lipid droplet density. J Biol Chem. 2013; 288:16274-16281.

43. Bhalla K, Hwang BJ, Dewi RE, Ou L, Twaddel W, Fang HB, Vafai SB, Vazquez F, Puigserver P, Boros L and Girnun GD. PGC1alpha promotes tumor growth by inducing gene expression programs supporting lipogenesis. Cancer Res. 2011; 71:6888-6898.

44. Zaytseva YY, Elliott VA, Rychahou P, Mustain WC, Kim JT, Valentino J, Gao T, O’Connor KL, Neltner JM, Lee EY, Weiss HL and Evers BM. Cancer cell-associated fatty acid synthase activates endothelial cells and promotes angiogenesis in colorectal cancer. Carcinogenesis. 2014; 35:1341-1351.

45. Tomek K, Wagner R, Varga F, Singer CF, Karlic H and Grunt TW. Blockade of fatty acid synthase induces ubiquitination and degradation of phosphoinositide-3kinase signaling proteins in ovarian cancer. Mol Cancer Res. 2011; 9:1767-1779.

46. Bajer MM, Kunze MM, Blees JS, Bokesch HR, Chen H, Brauss TF, Dong Z, Gustafson KR, Biondi RM, Henrich CJ, McMahon JB, Colburn NH, Schmid T and Brune B. Characterization of pomiferin triacetate as a novel mTOR and translation inhibitor. Biochem Pharmacol. 2014; 88:313-321.

47. Lamming DW and Sabatini DM. A Central role for mTOR in lipid homeostasis. Cell Metab. 2013; 18:465-469.

48. Roffe S, Hagai Y, Pines M and Halevy O. Halofuginone 
inhibits Smad3 phosphorylation via the PI3K/Akt and MAPK/ERK pathways in muscle cells: effect on myotube fusion. Exp Cell Res. 2010; 316:1061-1069.

49. Wang H and Joseph JA. Quantifying cellular oxidative stress by dichlorofluorescein assay using microplate reader. Free Radic Biol Med. 1999; 27:612-616. 